\title{
Late complication of cervical disc arthroplasty: heterotopic ossification causing myelopathy after 10 years. Illustrative case
}

\author{
Che-Han Hsu, MD, ${ }^{1}$ Yi-Hsuan Kuo, MD, ${ }^{1-3}$ Chao-Hung Kuo, MD, ${ }^{1,2,4}$ Chin-Chu Ko, MD, PhD, ${ }^{1,2}$ Jau-Ching Wu, MD, PhD, ${ }^{1,2}$ and \\ Wen-Cheng Huang, MD, $\mathrm{PhD}^{1,2}$

\begin{abstract}
${ }^{1}$ Department of Neurosurgery, Neurological Institute, Taipei Veterans General Hospital, Taipei, Taiwan; and ${ }^{2}$ School of Medicine, ${ }^{3}$ Institute of Biomedical Informatics, and ${ }^{4}$ Department of Biomedical Engineering, School of Biomedical Science and Engineering, National Yang Ming Chiao Tung University, Taipei, Taiwan
\end{abstract}

BACKGROUND Heterotopic ossification (HO) is a well-documented complication of cervical disc arthroplasty (CDA), although it rarely causes adverse clinical effects. Despite high-grade HO possibly limiting segmental mobility, it is reportedly seldom associated with symptoms.

OBSERVATIONS The authors report a case of a 46-year-old male patient who underwent hybrid CDA and anterior cervical discectomy and fusion for 3-level cervical disc herniation that caused myeloradiculopathy. The surgery was successful; the patient experienced nearly complete recovery postoperatively. The follow-up images, including computed tomography and magnetic resonance imaging scans, showed satisfactory decompression at the indexed levels without residual osteophytes or ossification of the posterior longitudinal ligament. However, 10 years later, the patient presented with symptomatic compressive myelopathy caused by severe $\mathrm{HO}$ that prompted a secondary surgery.

LESSONS Although it is generally reported in the literature that $\mathrm{HO}$ is clinically innocuous, in this patient, it gradually and progressively developed and caused myelopathy, requiring a secondary surgery. Symptomatic $\mathrm{HO}$ can be expected over time, and patients with a high risk of $\mathrm{HO}$ deserve long-term follow-up after CDA. Further investigations are warranted to corroborate these risk factors, including multilevel calcified disc herniation, severe spondylosis, and suboptimal placement of the device during primary CDA surgery.

https://thejns.org/doi/abs/10.3171/CASE21351

KEYWORDS myelopathy; heterotopic ossification; cervical disc arthroplasty; Prestige LP; laminectomy

Cervical disc arthroplasty (CDA) has been recognized as a safe and effective alternative to anterior cervical discectomy and fusion (ACDF) for patients with cervical myelopathy and radiculopathy caused by disc herniation or spondylosis. ${ }^{1-5}$ Many midterm to long-term reports of multicenter prospective randomized controlled trials have demonstrated the effectiveness of CDA in maintaining neurological improvement and preservation of segmental mobility. ${ }^{6-9}$ The potential to alleviate adjacent segment degeneration (ASD) with CDA has also been suggested but still needs long-term data for corroboration. ${ }^{6,10-13}$ However, the emerging popularity of CDA has raised the concern of heterotopic ossification $(\mathrm{HO})$, with variable incidence rates ranging from $2.9 \%$ to more than half of the patients over time among many series. ${ }^{14-18}$ Radiographically highgrade $\mathrm{HO}$ after CDA could certainly limit segmental mobility at the indexed level, but it rarely alters neurological improvement or clinical outcomes. $^{13,19-24}$ Although many risk factors and etiologies of $\mathrm{HO}$ after CDA have been studied, the reports have unanimously indicated that $\mathrm{HO}$ has little clinical consequence and seldom needs revision surgery. ${ }^{25-31}$

In this report, we present a case of late-onset compressive cervical myelopathy caused by gradually developed HO 10 years after CDA. To date, to our knowledge, this is the first case report on a late-onset development of $\mathrm{HO}$ after CDA that caused severe cervical stenosis and required a secondary surgery.

\section{Illustrative Case}

\section{Initial Presentation}

A 46-year-old male patient presented with clumsiness in both hands, muscle spasms, and unsteady gait after lumbar spine surgery at another

ABBREVIATIONS ACDF = anterior cervical discectomy and fusion; $A S D=$ adjacent segment degeneration; $C D A=$ cervical disc arthroplasty; $C T=$ computed tomography; $\mathrm{HO}=$ heterotopic ossification; $\mathrm{MRI}=$ magnetic resonance imaging; $\mathrm{OPLL}=$ ossification of the posterior longitudinal ligament. INCLUDE WHEN CITING Published August 23, 2021; DOI: 10.3171/CASE21351.

SUBMITTED June 9, 2021. ACCEPTED July 9, 2021.

(c) 2021 The authors, CC BY-NC-ND 4.0 (http://creativecommons.org/licenses/by-nc-nd/4.0/). 
hospital. Upon physical examination, paresthesia over C7-8 dermatomes and hyperreflexia in both legs were observed, accompanied by abnormal Babinski reflexes bilaterally. The radiographs demonstrated mild spondylotic changes with loss of lordosis at C5-7 levels (Fig. 1A). On the computed tomography (CT) scans, calcified discs at $\mathrm{C} 4-5$ and osteophytes at C5-6 were seen (Fig. 2A). Magnetic resonance imaging (MRI) showed severe disc herniation and spondylosis at the levels of C4-7 with significant spinal cord compression and increased intramedullary signal intensity on the T2-weighted MRI scan (Fig. 3A). On the basis of the aforementioned clinical symptoms, positive neurological signs, and compatible imaging evidence, the patient underwent a hybrid 2-level CDA at C4-6 (Prestige LP; Medtronic Sofamor Danek) and 1level ACDF with plate and screws. The original concept was to perform the decompression (anterior discectomy) thoroughly while maintaining the most possible motility (hybrid CDA and ACDF) rather than indirect decompression (posterior laminectomy) and fusion.

The immediate postoperative radiograph revealed satisfactory implant positions and restoration of the cervical lordotic curvature (Fig. 1B). The patient experienced significant improvement after surgery. His clumsiness and unsteady gait greatly recovered after several weeks. He was able to return to work and undertake normal daily activities.

Six months after surgery, a CT scan confirmed the adequacy of decompression for both the canal and the neuroforamen (Fig. 2B). Furthermore, at the 2.5-year postoperative follow-up, MRI demonstrated significant reexpansion of the previously compressed dural sac and almost complete recovery of the increased intramedullary signal intensity of the spinal cord (Fig. 3B). The hybrid CDA and ACDF (C4-6 and C6-7, respectively) surgery was successful for the myeloradiculopathy caused by 3 consecutive levels of disc herniation and severe spondylosis. By performing this procedure, a 3level fusion (i.e., 3-level ACDF) construct was successfully avoided, and relief of neurological symptoms was attained. Segmental mobility was also successfully preserved up to 10 years after the primary surgery, and the ACDF level appeared solid (Fig. 1C and D).

\section{Compressive Myelopathy From HO Formation}

Ten years after the primary surgery (i.e., hybrid CDA and ACDF), and having missed regular follow-up visits for years, the patient presented with progressive paresthesia over 4 limbs and recurrent gait disturbance for 3 months. There was such rapid deterioration of neurological function that he had to come to the clinic on crutches. Physical examination revealed gait ataxia and hyperreflexia in both legs. The dynamic lateral radiographs of the cervical spine demonstrated McAfee grade $2 \mathrm{HO}$ formation at C4-6 levels and a herniated disc at C3-4, which could be attributed to ASD (Fig. 1C and D).

The growth of $\mathrm{HO}$ significantly narrowed the spinal canal at C4-6 where the CDA levels were, whereas the C6-7 ACDF level had solid fusion and little stenosis (Fig. 2C). On the MRI scan taken 10 years after the primary surgery, there was severe spinal cord compression at levels C4-6 with worsened myelopathy, which could be indicated by the lengthy increased intramedullary signal intensity (Fig. 3C). Moreover, the electrophysiological examinations, including motor evoked potential evaluations, revealed bilateral corticospinal tract lesions above the C8 level, a mild degree for bilateral hands, and a moderate degree for bilateral feet. These results suggested recurrent multiple-level compressive cervical myelopathy caused by gradual formation of $\mathrm{HO}$ at the sites where previous CDA was successfully performed.

Because the compressive myelopathy was significant and lengthy, the patient was taken for posterior decompression and fusion 10 years after the primary surgery that had attempted decompression and preservation of motion. The patient then underwent a
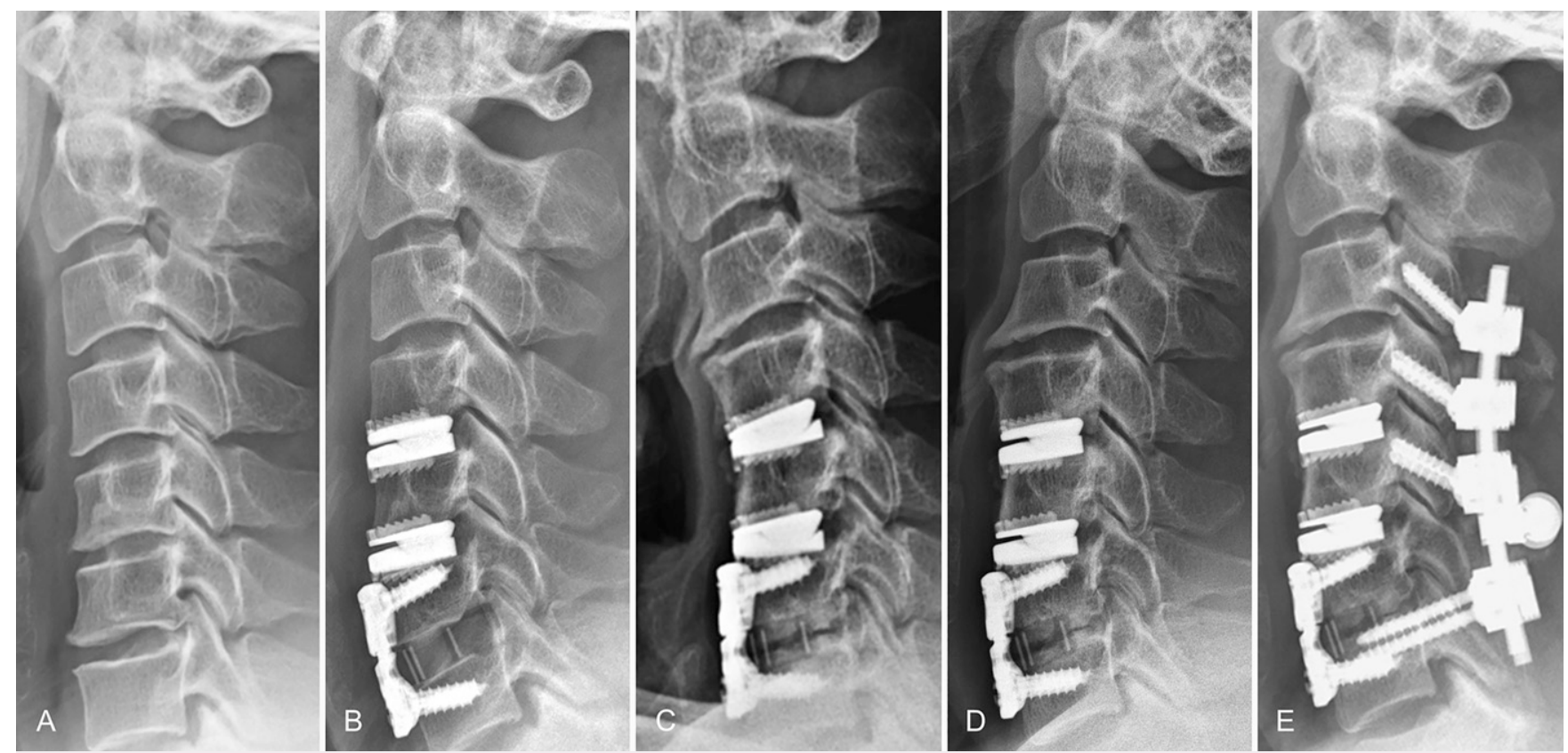

FIG. 1. A: Initial preoperative lateral radiograph. B: Immediate postoperative lateral radiograph showing partial restoration of cervical lordosis by the hybrid construct. C and D: Ten years after surgery, dynamic lateral radiographs showed marked degeneration, especially at adjacent C3-4, and nonbridging $\mathrm{HO}$ at C4-6 with preserved segmental mobility at these 2 levels, which also indicated McAfee grade $2 \mathrm{HO}$ formation at levels C4-6. E: Final lateral radiograph after salvage posterior decompression and instrumented fusion at C3-7. 

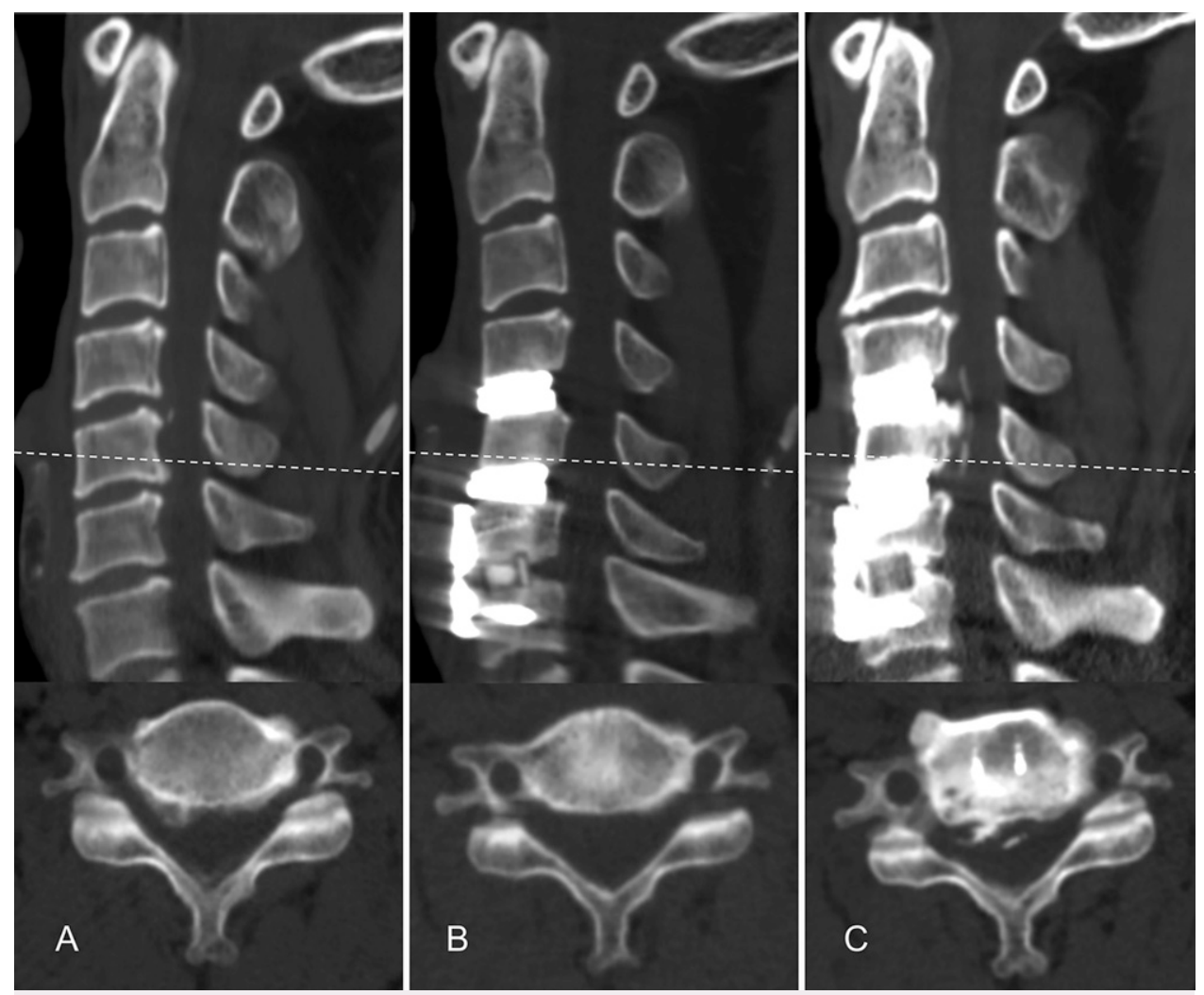

FIG. 2. A: Initial preoperative CT showing a calcified disc at C4-5 with marginal osteophytes in C5-6. B: Six months after surgery, the follow-up CT showed satisfactory decompression without any HO. C: Ten years after surgery, CT showed marked HO formation surrounding the artificial disc and epidural spaces at C4-6, which caused severe stenosis.

C3-7 laminectomy and instrumentation at C3-7 (Fig. 1E). The posterior surgery also went smoothly, and there were no surgical complications. Fortunately, the patient had neurological improvement after rehabilitation and was independently ambulatory after 3 months.

\section{Discussion}

We present a case of late-onset $\mathrm{HO}$ formation after CDA surgery that caused compressive myelopathy after 10 years. The patient had a primary anterior cervical discectomy for 3 levels that consisted of a hybrid reconstruction, including 2-level CDA and 1-level ACDF at $C 4-6$ and $C 6-7$, respectively. By coincidence, the patient had an internal control for comparison of the 2-level CDA to 1-level ACDF for the subsequent results after anterior cervical discectomy. The final images, including those from dynamic lateral radiographs, CT scans, and MRI, showed functioning (preserved segmental motility) of the CDA levels, despite massive $\mathrm{HO}$ formation that caused spinal stenosis and myelopathy. Moreover, the ACDF level demonstrated solid fusion and a well-decompressed canal size. The bottom-line observation from this patient indicated that, although the CDA preserved segmental mobility, its complication of $\mathrm{HO}$ formation was eventually problematic and required secondary decompression and fusion. The above-described history of the disease intuitively makes one wonder if the progression of cervical myelopathy could have been halted if the patient had received a 3-level ACDF up front. Although this phenomenon was inadequate to generalize opposition to CDA, it warrants further evaluation and longer-term follow-up of patients who undergo CDA surgery. It also implies that $\mathrm{HO}$ after CDA might not be as innocuous as the literature has suggested. Moreover, it should be noted that the currently available reports on U.S. Food and Drug Administration trials have only included 1- and 2-level CDA surgery; therefore, any CDA for more than 2 contiguous levels is considered off-label use.

The etiologies of $\mathrm{HO}$ remain elusive, and it has been rarely reported in industry-supported large-scale randomized controlled trials comparing CDA with $\mathrm{ACDF}^{4,5,13,16}$ However, in several retrospective cohorts outside of the United States, $\mathrm{HO}$ has been evaluated in smaller sample sizes. Potential risk factors for $\mathrm{HO}$ could be theoretically categorized into aspects of the patient-dependent, surgeon-dependent, and device-dependent risk factors. On the one hand, the reported risks included multilevel cervical spondylosis, calcified disc herniation, nonsmoker, advanced age, suboptimal installation of the device, lack of postoperative consumption of nonsteroidal anti-inflammatory drugs, preoperatively limited segmental mobility, and semiconstrained design of the device. 2,19-25,28,30-37 On the other hand, the clinically significant consequences caused by $\mathrm{HO}$ have rarely been reported. To the best of our knowledge, only one case was presented by Wenger et al. ${ }^{38}$ in 2016, in which HO-associated myelopathy nearly 9 years after CDA surgery with a Bryan disc (Medtronic Sofamor Danek) led to conversion to ACDF. 


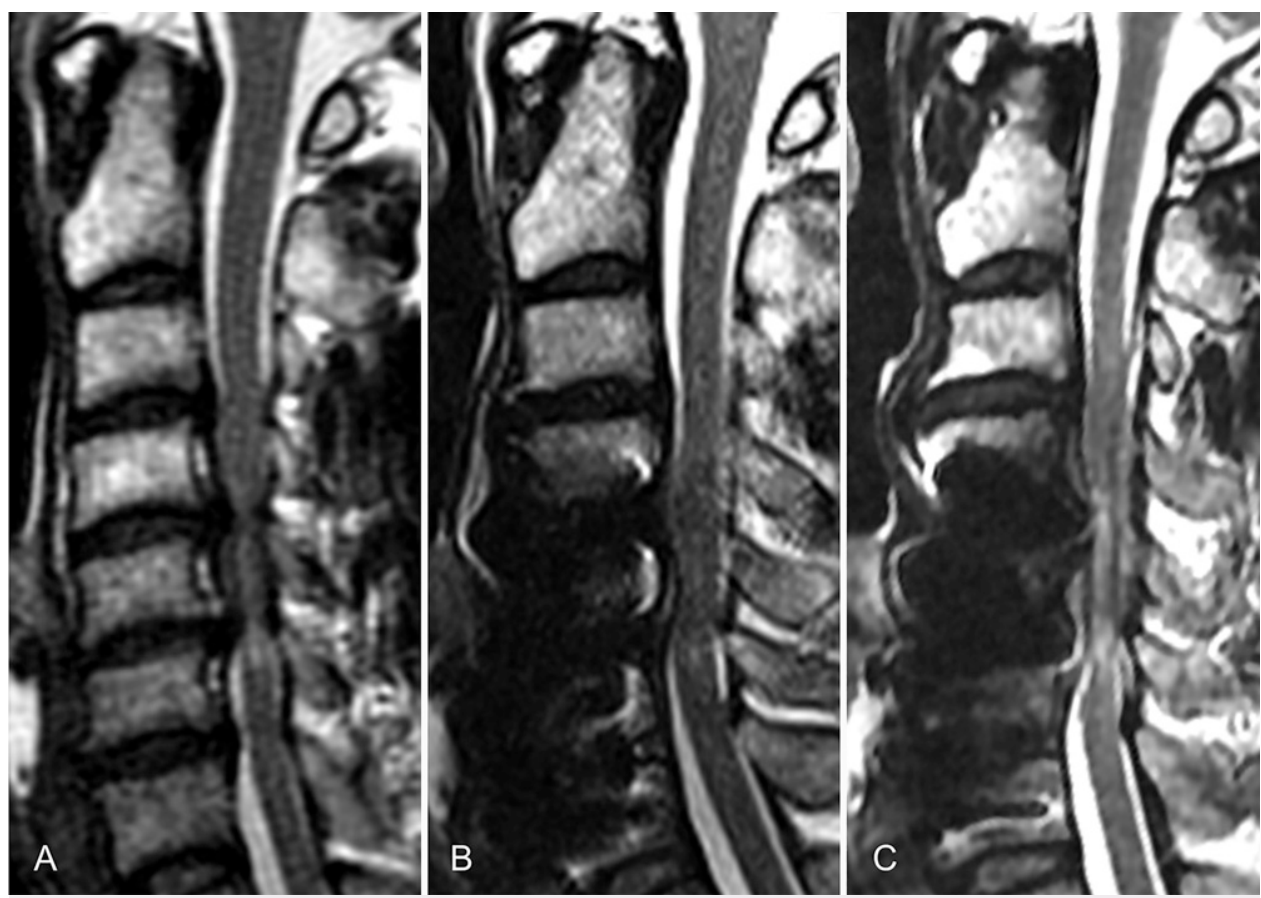

FIG. 3. A: Initial preoperative T2-weighted MRI scan showing herniated discs and spondylosis that caused spinal cord compression and increased intramedullary signal intensity, indicating myelopathy at C4-7.

B: Two and one-half years after surgery, follow-up MRI showed adequate reexpansion of the dural sac with improved intramedullary signal intensity. C: Ten years after surgery, MRI revealed severe spinal cord compression at C4-6 and lengthy increased intramedullary signal intensity, which indicated worsened myelopathy at the levels of CDA (C4-6), but not at the level of arthrodesis (C6-7).

However, the report provided little imaging support of the follow-up after the primary surgery. Thus, it inevitably raised the concern of residual osteophytes or preexisting segmental ossification of the posterior longitudinal ligament (OPLL).

The present report is the first, to our knowledge, to document progression of $\mathrm{HO}$ that eventually became clinically significant and required a secondary surgery. Furthermore, in terms of the type of prosthesis, the present report is also, to our knowledge, the first description of HO-associated myelopathy after 2-level Prestige LP (Medtronic Sofamor Danek) CDA surgery.

The true etiologies, risk factors, and consequences of $\mathrm{HO}$ warrant further investigation. Although many reports have demonstrated that $\mathrm{HO}$ might not be problematic for years after CDA, long-term evaluations are necessary to corroborate the eventual outcomes of $\mathrm{CDA}$ and to clarify the incidences of clinically significant $\mathrm{HO}$ with reference to its risk factors.

\section{Observations}

The authors report a case of a 46-year-old male patient who underwent hybrid CDA and ACDF for 3-level cervical disc herniation and spondylosis that caused myeloradiculopathy. The surgery was successful; the patient experienced almost complete recovery postoperatively. The follow-up images, including CT and MRI scans, showed satisfactory decompression at the indexed levels without residual osteophytes or OPLL. However, 10 years later, the patient presented with symptomatic compressive myelopathy caused by severe $\mathrm{HO}$ that prompted a secondary surgery.

\section{Lessons}

Although it is generally reported in the literature that $\mathrm{HO}$ is clinically innocuous, in this patient, $\mathrm{HO}$ gradually and progressively developed into a massive growth and caused myelopathy requiring a secondary surgery. Symptomatic HO may be expected over time, and patients with a high risk of $\mathrm{HO}$ deserve long-term follow-up after CDA. Further investigations are warranted to corroborate these risk factors, including multilevel calcified disc herniation, severe spondylosis, and suboptimal placement of the device during primary CDA surgery.

\section{References}

1. Gornet MF, Lanman TH, Burkus JK, et al. Two-level cervical disc arthroplasty versus anterior cervical discectomy and fusion: 10-year outcomes of a prospective, randomized investigational device exemption clinical trial. J Neurosurg Spine. 2019;31(4):508-518.

2. Fay LY, Huang WC, Wu JC, et al. Arthroplasty for cervical spondylotic myelopathy: similar results to patients with only radiculopathy at 3 years' follow-up. J Neurosurg Spine. 2014;21(3):400-410.

3. Fay LY, Huang WC, Tsai TY, et al. Differences between arthroplasty and anterior cervical fusion in two-level cervical degenerative disc disease. Eur Spine J. 2014;23(3):627-634.

4. Mummaneni PV, Amin BY, Wu JC, Brodt ED, Dettori JR, Sasso RC. Cervical artificial disc replacement versus fusion in the cervical spine: a systematic review comparing long-term follow-up results from two FDA trials. Evid Based Spine Care J. 2012;3(suppl 1):59-66.

5. Upadhyaya CD, Wu JC, Trost G, et al. Analysis of the three United States Food and Drug Administration investigational device exemption cervical arthroplasty trials. J Neurosurg Spine. 2012;16(3): 216-228. 
6. Coric D, Guyer RD, Nunley PD, et al. Prospective, randomized multicenter study of cervical arthroplasty versus anterior cervical discectomy and fusion: 5-year results with a metal-on-metal artificial disc. J Neurosurg Spine. 2018;28(3):252-261.

7. Nunley PD, Coric D, Frank KA, Stone MB. Cervical disc arthroplasty: current evidence and real-world application. Neurosurgery. 2018;83(6):1087-1106.

8. Kim K, Hoffman G, Bae H, et al. Ten-year outcomes of 1- and 2-level cervical disc arthroplasty from the Mobi-C investigational device exemption clinical trial. Neurosurgery. 2021;88(3):497-505.

9. Parish JM, Coric D. Cervical arthroplasty: long-term outcomes of FDA IDE trials. Global Spine J. 2020;10(2 suppl):61S-64S.

10. Goldstein ZH, Boody B, Sasso R. Two-level anterior cervical discectomy and fusion versus cervical disc arthroplasty-long-term evidence update. Int J Spine Surg. 2020;14(suppl 2):S36-S40.

11. Sasso WR, Smucker JD, Sasso MP, Sasso RC. Long-term clinical outcomes of cervical disc arthroplasty: a prospective, randomized, controlled trial. Spine (Phila Pa 1976). 2017;42(4):209-216.

12. Gornet MF, Lanman TH, Burkus JK, et al. One-level versus 2-level treatment with cervical disc arthroplasty or fusion: outcomes up to 7 years. Int J Spine Surg. 2019;13(6):551-560.

13. Gornet MF, Lanman TH, Burkus JK, et al. Occurrence and clinical implications of heterotopic ossification after cervical disc arthroplasty with the Prestige LP Cervical Disc at 2 contiguous levels. J Neurosurg Spine. 2020;33(1):41-50.

14. Tu TH, Wu JC, Huang WC, et al. Heterotopic ossification after cervical total disc replacement: determination by $\mathrm{CT}$ and effects on clinical outcomes. J Neurosurg Spine. 2011;14(4):457-465.

15. Brenke C, Scharf J, Schmieder K, Barth M. High prevalence of heterotopic ossification after cervical disc arthroplasty: outcome and intraoperative findings following explantation of 22 cervical disc prostheses. J Neurosurg Spine. 2012;17(2):141-146.

16. Gornet MF, Burkus JK, Shaffrey ME, Schranck FW, Copay AG. Cervical disc arthroplasty: 10-year outcomes of the Prestige LP cervical disc at a single level. J Neurosurg Spine. 2019;31(3): 317-325

17. Murrey DB, Janssen ME, Odum SM, Gottlieb JR, Spector LR, Darden BV. Two-year results of a randomized controlled clinical trial comparing ProDisc-C and anterior cervical discectomy and fusion. SAS J. 2008;2(2):76-85.

18. Loumeau TP, Darden BV, Kesman TJ, et al. A RCT comparing 7-year clinical outcomes of one level symptomatic cervical disc disease (SCDD) following ProDisc-C total disc arthroplasty (TDA) versus anterior cervical discectomy and fusion (ACDF). Eur Spine J. 2016;25(7):2263-2270.

19. Chang PY, Chang HK, Wu JC, et al. Differences between C3-4 and other subaxial levels of cervical disc arthroplasty: more heterotopic ossification at the 5-year follow-up. J Neurosurg Spine. 2016;24(5): 752-759.

20. Chang HK, Huang WC, Tu TH, et al. Radiological and clinical outcomes of 3-level cervical disc arthroplasty. J Neurosurg Spine. 2019;32(2):174-181.

21. Tu TH, Kuo CH, Huang WC, Fay LY, Cheng H, Wu JC. Effects of smoking on cervical disc arthroplasty. J Neurosurg Spine. 2019; 30(2):168-174.

22. Tu TH, Lee $\mathrm{CY}$, Kuo $\mathrm{CH}$, et al. Cervical disc arthroplasty for lessmobile discs. J Neurosurg Spine. 2019;31(3):310-316.

23. Wu JC, Chang HK, Huang WC, et al. Radiological and clinical outcomes of cervical disc arthroplasty for the elderly: a comparison with young patients. BMC Musculoskelet Disord. 2019;20(1):115.

24. Kuo $\mathrm{YH}$, Kuo $\mathrm{CH}$, Chang $\mathrm{HK}$, et al. The effect of T1-slope in spinal parameters after cervical disc arthroplasty. Neurosurgery. 2020; 87(6):1231-1239.

25. Chang HK, Chang CC, Tu TH, et al. Can segmental mobility be increased by cervical arthroplasty? Neurosurg Focus. 2017;42(2):E3.
26. Chang HK, Huang WC, Wu JC, et al. Should cervical disc arthroplasty be done on patients with increased intramedullary signal intensity on magnetic resonance imaging? World Neurosurg. 2016;89:489-496.

27. Chang HC, Tu TH, Chang HK, et al. Hybrid corpectomy and disc arthroplasty for cervical spondylotic myelopathy caused by ossification of posterior longitudinal ligament and disc herniation. World Neurosurg. 2016;95:22-30.

28. Chang HK, Huang WC, Wu JC, et al. Cervical arthroplasty for traumatic disc herniation: an age- and sex-matched comparison with anterior cervical discectomy and fusion. BMC Musculoskelet Disord. 2015;16:228.

29. Wu JC, Huang WC, Tu TH, et al. Differences between soft-disC herniation and spondylosis in cervical arthroplasty: CT-documented heterotopic ossification with minimum 2 years of follow-up. J Neurosurg Spine. 2012;16(2):163-171.

30. Wu JC, Huang WC, Tsai TY, et al. Multilevel arthroplasty for cervical spondylosis: more heterotopic ossification at 3 years of followup. Spine (Phila Pa 1976). 2012;37(20):E1251-E1259.

31. Wu JC, Huang WC, Tsai HW, et al. Differences between 1- and 2-level cervical arthroplasty: more heterotopic ossification in 2-level disc replacement: clinical article. J Neurosurg Spine. 2012;16(6): 594-600.

32. Chang PY, Chang HK, Wu JC. Cervical disc arthroplasty: nonconstrained versus semiconstrained. J Neurosurg Spine. 2015;23(3):394-395.

33. Chang PY, Chang HK, Wu JC, et al. Is cervical disc arthroplasty good for congenital cervical stenosis? J Neurosurg Spine. 2017; 26(5):577-585.

34. Tu TH, Wu JC, Huang WC, et al. Postoperative nonsteroidal antiinflammatory drugs and the prevention of heterotopic ossification after cervical arthroplasty: analysis using CT and a minimum 2-year follow-up. J Neurosurg Spine. 2015;22(5):447-453.

35. Tu TH, Wu JC, Huang WC, Wu CL, Ko CC, Cheng $H$. The effects of carpentry on heterotopic ossification and mobility in cervical arthroplasty: determination by computed tomography with a minimum 2-year follow-up: clinical article. J Neurosurg Spine. 2012;16(6):601-609.

36. Chang CC, Huang WC, Wu JC, Mummaneni PV. The option of motion preservation in cervical spondylosis: cervical disc arthroplasty update. Neurospine. 2018;15(4):296-305.

37. Huang WC, Wu JC. Preservation versus elimination of segmental motion in anterior cervical spine surgery. Neurospine. 2019;16(3): $576-578$.

38. Wenger M, Markwalder TM. Heterotopic ossification associated with myelopathy following cervical disc prosthesis implantation. J Clin Neurosci. 2016;26:154-156.

\section{Disclosures}

The authors report no conflict of interest concerning the materials or methods used in this study or the findings specified in this paper.

\section{Author Contributions}

Conception and design: Ko, Hsu, Wu, Huang. Acquisition of data: Hsu, Y.-H. Kuo, Huang. Analysis and interpretation of data: Hsu, Y.-H. Kuo, C.-H. Kuo, Wu, Huang. Drafting the article: Hsu, Wu. Critically revising the article: Ko, Wu. Reviewed submitted version of manuscript: Ko, $\mathrm{Hsu}, \mathrm{Wu}$. Approved the final version of the manuscript on behalf of all authors: Ko. Administrative/technical/material support: C.-H. Kuo, Wu. Study supervision: Ko, Wu, Huang.

\section{Correspondence}

Chin-Chu Ko: Neurological Institute, Taipei Veterans General Hospital, Taipei, Taiwan. hansamu0627@gmail.com. 